\title{
"By the Numbers:” Language-based and Competency Enhancing Math Instruction to Alleviate Older Women’s Math Stereotype Threat Reactions
}

\author{
Lisa Hollis-Sawyer ${ }^{1, *}$ \& Thomas P. Sawyer, Jr. ${ }^{2}$ \\ ${ }^{1}$ Department of Psychology, Northeastern Illinois University, Chicago, IL 60625, USA \\ 2 Department of Psychology, Elmhurst College, Elmhurst, IL 60126, USA \\ *Corresponding author: Northeastern Illinois University, Department of Psychology, M.A. in \\ Gerontology Program, Brommel Building, BBH 307E, 5500 N. St. Louis Avenue, Chicago, \\ IL 60625, USA. E-mail: l-hollissawyer@neiu.edu
}

Received: July 9, 2014 Accepted: September 3, $2014 \quad$ Published: September 23, 2014

doi:10.5296/ije.v6i3.5949ＵRL: http://dx.doi.org/10.5296/ije.v6i3.5949

\begin{abstract}
Haack (1979) purported that the use of language in math-related statistics instruction (i.e., "statistical literacy") is a good instructional approach to teach introductory statistics to learners. Extending current stereotype threat research on women, older adults, and math, the present research explored math-related anxiety and test performance outcomes between younger ("traditional") and older ("non-traditional”) women college learners in four different instructional conditions ("math as language/competency enhancing," "math as language/competency destroying," "math as numbers/competency enhancing," and "math as numbers/competency destroying,"). An exploratory investigation examined whether the "math as language/competency enhancing" would elicit significant and assistive "self schema" linkages with positive gender performance ("women are better at verbal tasks" concept) and aging-related expertise ("older adults have accumulated language skills" concept) positive stereotypes based on past language-related socialization experiences for women and older adults. The positive impact of the "math as language/competency enhancing" instructional condition in preliminary results appeared to benefit both younger and older women learners in both personal attitudes toward math ability, general learning capability, and testing performance behaviors. Analyses by age level supported the idea of a math-related "decrement" stereotype threat belief among the older women learners, in comparison to younger women learners, across learning conditions.
\end{abstract}

Keywords: stereotype threat, math instruction, math self-efficacy, age differences, testing 


\section{Introduction}

There will be an increasing presence of older women learners on college campuses (U.S. Education Department, National Center for Education Statistics, 2008) and other educational settings (e.g., work-related training) in the coming decades, and it is vital to address their unique learning needs and motivations (e.g., Principi \& Lamura, 2009). Math education is an important area for women that needs further examination. Math efficacy can directly impact women's educational and career pursuits across the life span into later life, creating "barriers" where there should be only opportunities (e.g., Brodish \& Devine, 2009; Hart, Petrill, Thompson, \& Plomin, 2009; Hartman \& Hartman, 2008), and potentially creating a detrimental cycle of negative self-evaluation and restrictive life choices. Social stereotypes exist for women learning math (e.g., “women can’t do math” stereotype belief). The general objectives of the research study was to more closely examine this phenomenon for older ("non-traditional”) women learners from a possible "double jeopardy” effect (i.e., combined "women and math" and "older learners and cognitive decline” decrement stereotypes) and, from a positive gaining perspective, to explore specific instructional strategies for minimizing the impact of this potential combined double jeopardy stereotype reaction. Extending Haack's (1979) finding of language-based statistics instruction (i.e., "statistical literacy”) as a good instructional approach, the present research examined the use of language and efficacy enhancement in math instruction with older women learners.

The following will explain how this research meaningfully extends knowledge in the fields of math education, women's studies, and gerontology. Specifically, the proceeding literature review will begin by presenting research on Stereotype Threat Theory as a conceptual framework for the research. The literature review will then introduce research that relates and extends Stereotype Threat Theory to the topics of women and math anxiety and older learner efficacy issues. Finally, the resultant discussion of the literature will culminate with an examination of the combination of these two areas or a "double jeopardy" hypothesis related to the potential stereotype threat reaction of relatively older ("non-traditional”) women learners in a math-related learning and testing context.

\section{Stereotype Threat as a Conceptual Framework}

"Stereotype threat" as a concept has been offered as a possible explanation for subgroup differences in task persistence and testing performance (Aronson, Quinn, \& Spencer, 1998;

Grimm, Markman, Maddox, \& Baldwin, 2009; Major, Spencer, Schmader, Wolfe, \& Crocker, 1998; Steele, 1997; Steele \& Ambady, 2006; Steele \& Aronson, 1998). Stereotype threat theory states that people who perceive themselves to be of a certain identifiable group (e.g., by gender) may experience a performance decrement during testing because of a concern that their performance will substantiate a negative, widely-held stereotype about this group (e.g., stereotype that women do less well in math than men) (Schweinle \& Mims, 2010; Spencer, 1999). Stereotype threat as a reaction has been theorized to operate through a variety of mechanisms, including cognitive (e.g., distracting thoughts; Beilock, Jellison, Rydell, 
McConnell, \& Carr, 2006), motivational (e.g., persistence; O'Brien \& Crandall, 2003), and emotional (e.g., anxiety; Brodish \& Devine, 2009) processes. The stereotype threat "self schema” can become an internalized, unconscious process that affects girl's math performance (e.g., Galdi, Cadinu, \& Tomasetto, 2014).

\section{Women, Aging, and Math: Extension of Stereotype Threat Concept}

One area of math-related instructional research which has not been applied to stereotype threat has been the age of the individual and how cohort-related attitudes may underlie test anxiety reactions for older women learners. There may be a "double jeopardy" issue, in that older women both believe that they would not do well on math tests due to their sex (e.g., Eccles \& Jacobs, 1986) and do to their age (e.g., Cross \& Florio, 1978, pp. 9-11; Luckie, 1999). Self-concept has been identified as an important educational issue with older adult learners. Perceived barriers to learning and the perceived ability to learn new concepts can significantly impact older adults' academic performance and their willingness to engage in life-long learning (Drummond \& Gilkison, 1989; Holtzclaw, 1985; Lemieux, 1997). Research in college settings indicate different learning motivations between younger and older adult learners, in that older learners are motivated by more internal factors (e.g., self-satisfaction) (O’Connor, 1987). This is important for educators to understand, because older learners with existing negative self-evaluation beliefs may be more detrimentally impacted by contexts eliciting stereotype threat reactions.

Older learners have unique educational support needs and testing issues, necessitating educational programs to be designed to reduce perceived barriers and increase mastery experiences (Galbraith \& James, 1984; Howard \& Wiggs, 1993; Kuznar, Falciglia, Wood, \& Frankel, 1991; Lynch \& Sellers, 1996; Shaughnessy \& Reif, 1987; Willis, 1985). Although past research on age-related differences in math anxiety has not been as extensive as sex-difference research, there is support for the idea that older learners may be more susceptible to math anxiety in academic settings (Cook, 1998; Hopko, Ashcraft, Gute, Ruggiero, \& Lewis, 1998; Kostka \& Wilson, 1986). The specific supposition of the present study is that older adults in a "competency destroying” learning context (i.e., learning material is not presented in a familiar and meaningful manner) will unconsciously access a negative self-belief of “old dogs can’t learn new tricks.” The present study, among other purposes, will examine factors explaining why this may occur with older learners, and whether there is an interaction effect between age level and sex. This has obvious implications toward pedagogical approaches to teaching older adult learners in ways that reduce anxiety and improve learning performance.

\section{Rationale for Math Instruction Research Design}

Proper program design in academic and other contexts can effectively reduce women's math anxiety reactions and improve math performance, breaking the detrimental cycle of negative self-evaluation and restrictive life choices. Past research suggests that women especially 
benefit from specific math-related training in ways to reduce math anxiety in an academic context (e.g., Llabre \& Suarez, 1985). Interestingly, women who attribute math-related performance success to behavioral (internal) causes, and have had positive past math-related experiences, are more likely to have a better math self-concept (Bandalos, Yates, \& Thorndike Christ, 1995; Betz, 1978; Hunsley \& Flessati, 1988).

The first instructional framework level relates to mode of presenting information to math learners (independent variable \#1). According to the instructional condition assigned (i.e., "math as numbers" or "math as language"), participants may be trained within a course orientation that "frames" the proceeding math instruction and testing. Haack (1979) discussed this idea of "statistical literacy," making the supposition that this approach would be best to teach introductory statistics to learners. This idea has been extended to the use of language in math instruction for the present study. Past research suggests that more "responsive" instructional environments can help younger girls (and boys) make more positive associations between math and personal capabilities (Griggs, Rimm-Kaufman, Merritt, \& Patton, 2013), and the association between literacy skills and math performance has already showed some beneficial associations for adolescent girls learning math (e.g., Kyttala \& Bjorn, 2014).

It was hypothesized that this instructional condition approach would elicit "self schema" linkages with positive gender ("women are better at verbal tasks") and aging-related expertise (“older adults have accumulated language skills”) stereotypes based on past language-related socialization experiences. In the first instructional condition (i.e., "math as numbers"), a math-related subject is presented using several number/formula examples and practice work associated within this "self schema" orientation. Learners are taught how to cognitively process math problems in a more conceptual manner within a traditional instructional framework of using numbers and formulas. Math was stressed as a useful tool for finding a correct answer. It was hypothesized that this primed self schema would elicit associative linkages with negative gender stereotypes based on past math-related socialization experiences for women (e.g., past “math” role models). In the second condition (i.e., “math as language”), participants were trained within a course orientation that frames the proceeding math instruction and testing as a language-related subject with several word problem examples and practice work associated with this schema orientation. Learners are taught how to cognitively process statistical problems in a more conceptual manner within a novel instructional framework of using words and language. Math was presented as a tool for communicating results among professionals.

The second instructional framework relates to how the learning task itself is presented to learners. The "Competence Destroying" condition will offer a course orientation that "frames" the statistics learning task as a new knowledge base to be learned (i.e., negative transfer of existing knowledge bases) and only is used in conducting data analyses in research studies (i.e., low meaningfulness for everyday activities). Learners are taught how to cognitively process statistical problems in an empirical, research-driven manner within a traditional instructional framework of using research study examples (e.g., understanding math in a study). 
It was hypothesized that this schema development elicits associative linkages with negative aging-related stereotypes (i.e., inability to learn new concepts) for "non-traditional” learners. Conversely, the "Competence Enhancing" condition will offer a course orientation that "frames" the statistics-learning task as a positive transfer of existing knowledge and can be meaningfully applied toward everyday activities. Learners are taught how to cognitively process math problems in a more applied manner within a novel instructional framework of using past familiar examples (e.g., understanding statistics in newspaper statistical polls). It is hypothesized that this schema development elicits associative linkages with positive aging-related stereotypes (i.e., accumulated wisdom) based on past accomplishments for “non-traditional” learners.

Finally, developmental experiences with significant role models (e.g., a parent's attitudes and judgments about child's math ability; Bleeker \& Jacobs, 2004) was conducted using an ethnographic qualitative analysis approach and the results were analyzed by words, phrases, and themes to better understand in an exploratory manner this impact on women. Information gathered in this study has pedagogical implications for the teaching, testing, and feedback regarding class performance on math-related topics (e.g., statistics) in higher education.

\section{Research Design}

In order to identify the best educational interventions for both younger and older women learners, it is important to assess different social conditions ("instructional frameworks") of learning and assessment. The present research examined a 2 X 2 instructional framework conditions to potentially address the math-related learning needs of both younger and older women learners. The first independent variable relates to mode of instruction (numbers or language) and the second independent variable represented the level of competency support in instruction (enhancing or destroying). See Figure 1.

\begin{tabular}{|l|l|l|}
\hline \multirow{2}{*}{$\begin{array}{l}\text { Instructional Framework \#1 } \\
\text { (Two Levels): }\end{array}$} & \multicolumn{2}{|l|}{$\begin{array}{l}\text { Instructional Framework \#2 (Two Levels): } \\
\text { Competence Enhancing (1) or Competence Destroying (2) }\end{array}$} \\
\hline \multirow{3}{*}{$\begin{array}{l}\text { Math as Numbers (1) or } \\
\text { Math as Language (2) }\end{array}$} & $\begin{array}{l}\text { Math as Numbers; } \\
\text { Competence Enhancing }\end{array}$ & $\begin{array}{l}\text { Condition \#2: } \\
\text { Competence Destroying }\end{array}$ \\
\cline { 2 - 3 } & Condition \#3: & Condition \#4: \\
& Math as Language; & Math as Language; \\
& Competence Enhancing & Competence Destroying \\
\hline
\end{tabular}

Figure 1. Testing conditions examined (2 x 2 design)

The age level of women who participated in the research study was the pseudo-independent variable. 


\section{Study Aim and Hypotheses}

The specific aims of the research study were three fold: (1) extend existing research on women and math anxiety by assessing potential differences between younger and older women on math-related attitudes and test performance, (2) assess the degree to which four different combinations of math instruction approaches (e.g., "math as language/competency enhancing”) may affect women's learning attitudes and behavior, math test efficacy reactions and math test performance with a diverse sample of "traditional" and "non-traditional" women learners; and (3) investigate the impact of math-related role models on subsequent gender socialization, math-related efficacy, and learning performance issues of women learners (post-test interviews). The present research posed the following hypotheses to be evaluated through the age group comparisons and implemented math instruction conditions:

1. Are traditional and non-traditional women significantly different in math-related attitudes and math test performance?

2. Will different instructional conditions impact participants' math attitudes (e.g., stereotype threat reaction) and/or test performance?

3. Do past math-related role models have a meaningful and long-term impact on women's math self efficacy?

\section{Methodology}

\subsection{Study Participants}

The total sample was $n=114$ undergraduate college students across upper-level educational levels (i.e., junior, and senior levels). Seventy eight "traditional” college women (i.e., ages 18-27; $21.4(1.3)$ ) women ( $n=39$ ) and 36 "Non-traditional” college women (i.e., ages 45 - 64; 56.2 (1.1)) were recruited from a large diverse mid-western university. The designation of "age 45 and older" reflects the operational definition of a relatively older "non-traditional" learner on a typical college campus. Participants were diverse in race/ethnicity. Please refer to Table 1 for the distribution of participants' race/ethnicity by the associated age levels. Participation involved about one (1) hour of time.

\subsection{Measures}

A record sheet was used for each learner to record her time estimate for studying the math skills manual. On this same sheet, the researchers recorded the actual time each learner studied the math manual prior to taking the test. A brief demographic sheet is also administered.

A tape recorder was used to record participants' oral answers when asked to describe the cognitive processes or strategies used to study for the test, and recollections of past or current math-related role model(s) that affected his/her perceptions of personal math ability.

A developed 30-item math test covering a domain of math knowledge from upper division college level Math textbooks was used to assess participants' math performance. The test was 
developed and pilot tested during Spring 2011 with a sample of undergraduate students $(n=$ 24). Pilot testing assisted in reducing an original pool of 55 to 30 items; initial analyses indicate good inter-item reliability (.92). The more difficult items, identified through pilot testing, were presented first to heighten participants' math test anxiety/self-efficacy reaction. In addition, a three-page math review handout was developed and administered to participants in order to assess effort expended, etc. during studying time before testing.

Questionnaire \#1 assessed the following three test reaction dimensions: (1) evaluation apprehension (items 1-5) (based on Spencer, Steele, \& Quinn, 1999); (2) math self-efficacy (items 69) (based on Spencer, et al., 1999), and (3) math anxiety (items 10-14) (based on Spencer, et al., 1999). Respondents were asked to judge the degree to which statements reflect their self-image (i.e., ranging from “extremely not like me” to “extremely like me” on a 6-point scale). Because items were revised from the original source, only current pilot test results toward reliability can be reported. Pilot testing revealed initial inter-item consistency of items to range from .86 to .89 within sub dimensions (Hollis-Sawyer \& Sawyer, 2008).

Questionnaire \#2 assessed participants' belief in stereotype threat and test bias (items 1-4), based on Steele and Aronson (1995), personal beliefs about one's own cognitive aging and later-life learning ability and perceptions of society's associated attitudes (items 5-14), and belief in the malleability of intelligence, based on Dweck, Chui, and Hong (1995) (items 15-20; degree of "decrement" or rigidity in intelligence over time assessed). Respondents were instructed to respond to each item, ranging from "Strongly Agree" to "Strongly Disagree" on a 5-point scale. Because items were revised from the original source, only current pilot test results toward reliability can be reported. Previous pilot testing revealed initial inter-item consistency ranging from .90 to .95 within sub dimensions (Hollis-Sawyer \& Sawyer, 2008).

Questionnaire \#3 assessed participants' levels of tests anxiety, revising items sampled from the Friedben scale of test anxiety (Friedman \& Bendas-Jacob, 1997). The three sub dimensions of the scale are: (1) Social Derogation (items 1-8), (2) Cognitive Obstruction (items 9-17), and (3) Physical Tenseness (items 18-23). Respondents were asked to judge the degree to which statements reflect their self-image (i.e., ranging from "Extremely Not Like Me" to "Extremely Like Me" on a 6-point scale). Because items were revised from the original source, only current pilot test results toward reliability can be reported. Previous pilot testing revealed initial inter-item consistency of items to range from .84 to .86 within sub dimensions (Hollis-Sawyer \& Sawyer, 2008).

\subsection{Procedure}

Tested in groups of four to six people, participants were randomly assigned by age group to one of the four instructional conditions (i.e., "Math as Numbers/Competence Enhancing," "Math as Numbers/Competence Destroying," Math as Language/Competence Enhancing," or "Math as Language/Competence Destroying,"). Participants were first told that the purpose of their participation was to review a new self-study three-page math review handout for "user friendliness," and to take an associated math skills test. Study participants were told that they will receive their math test scores prior to leaving the study. Next, attendees were given an informed consent form to read silently as one of the researchers read it aloud to them, and 
attendees were instructed to sign if consenting to participate. Those consenting continued in the study, and those who did not consent were thanked for their time. Before proceeding, participants were asked to complete a brief demographic sheet asking for gender and age.

Next, questionnaire \#1 of baseline measures was administered and collected upon completion. Next, the math review handout was distributed and participants were asked to record on the record sheet the amount of time needed to review the manual for the up-coming test. The record sheet was then collected Based on random assignment to instructional condition by age level, the associated instructional "framework" information was conveyed. Under the randomly assigned research condition, an associated math review handout will be distributed and reviewed with the researcher. Participants were instructed to follow along with the researcher's review of the handout content and examples, and then independently review the three-page math review handout until they are ready to take the test indicated by placing the study handout face down on the desk. Using a stopwatch designated for each examinee, the researchers recorded the actual studying times for each participant on the corresponding collected record sheets.

After collecting the math review handout, the test was administered. The testing approach in the "language" presented math problems in verbal terms with a minimal use of numerals, while the testing approach under the "numbers" condition presented math problems in only numerical terms with minimal use of language in content. Participants were instructed to turn over their tests when completed. Completed tests were collected and participants were told that they were scored. Participants were told that the following surveys given were "time fillers" until the scores could be determined, and participants were then given Questionnaires \#2- \#3 consecutively to complete.

Next, following collection of the questionnaires, the primary researcher asked participants about the process or strategies used to study the math review handout, perceptions of personal learning capabilities in a math testing situation, and recollections of significant math role model(s) that affected his/her life, using a tape recorder to record the responses for later coded transcription. Finally, study participants were fully debriefed on the purpose of the study and any questions regarding the study was answered. At the time of study debriefing, each participant was interviewed by the researchers and his/her reactions to the math-learning task were discussed, with a corresponding discussion of ways to alleviate disruptive test anxiety reactions.

\section{Results}

The general objectives of the research study was to more closely examine this phenomenon women and math stereotype threat reactions by examining a possible aging-related "double jeopardy" effect (i.e., combined "women and math" and "older learners and cognitive decline" decrement stereotypes) and, from a positive aging perspective, to explore specific instructional strategies for minimizing the impact of this potential combined double jeopardy stereotype reaction in a math-related educational environment. The study sample was diverse in terms of 
race/ethnicity (refer to Table 1). The following results are presented in response to the posed hypotheses.

Table 1. Total number of each racial/ethnic category of women by age-level

\begin{tabular}{lccc}
\hline & Younger & Older & Subtotals \\
\hline $\begin{array}{l}\text { Caucasian/White } \\
\text { (Non-Hispanic) }\end{array}$ & 43 & 21 & 64 \\
\hline African-American & 18 & 8 & 26 \\
\hline Hispanic/Latino & 17 & 6 & 23 \\
\hline Asian-American & 0 & 1 & 1 \\
\hline $\begin{array}{l}\text { Native } \\
\text { American/Alaskan }\end{array}$ & 0 & 0 & 0 \\
\hline Total & 78 & 36 & 114 \\
\hline
\end{tabular}

\subsection{Hypothesis \#1: Age-level Comparisons in Attitudinal and Performance Outcomes}

The first study hypothesis examined whether age level differences (traditional and non-traditional college age) amongst college women were significantly different in math-related attitudes and math test performance. Refer to Table 2 for this section of results. Across measures presented, please note that higher scores indicated higher levels of anxiety and negative reactions unless otherwise indicated. The first math-related attitudinal measure assessed was examinees' general feelings of evaluation apprehension. There were significant differences between younger and older women $(t(113)=-3.10, p<.001)$, with older women being significantly higher on this self-report measure.

Table 2. Means (M) and standard deviations (SD) of math-related scores by age level

\begin{tabular}{lll}
\hline & $\begin{array}{l}\text { Younger } \\
(n=78) \\
M(S D)\end{array}$ & $\begin{array}{l}\text { Older } \\
(n=36) \\
M(S D)\end{array}$ \\
\hline Math test & $25.6(7.2)$ & $25.3(7.7)$ \\
\hline Math self-efficacy & $19.7(4.1)$ & $23.2(2.6)$ \\
\hline Math anxiety & $18.2(2.8)$ & $23.8(2.3)$ \\
\hline Math study time (estimated) & $5.1(0.6)$ & $5.0(0.9)$ \\
\hline Math study time (actual) & $3.2(0.7)$ & $6.8(1.7)$ \\
\hline
\end{tabular}

Note. A higher score on the math self-efficacy scale indicates lower levels of math-related efficacy regarding personal math capabilities.

The next attitudinal measures examined were math self-efficacy and math anxiety. With the math self-efficacy measure, higher scores indicated lower levels of math-related self-efficacy and associated negative reactions. Older women were significantly lower in math-related self efficacy (higher scores) at the .001 level $(t(113)=-2.64, p<.001)$ and significantly higher in mean scores on math anxiety at the .001 level $(t(113)=-2.92, p<.001)$.

There were no significant differences between older and younger women regarding estimated 
study time needed to review the math study hand-out prior to testing $(p>.001)$. However, older women spent significantly longer studying than younger women $(t(113)=-2.89, p<.001)$. Interestingly, there were no significant differences in actual test performance by age level $(p>.05)$ (e.g., overall: $t(113)=.18, p>.05$ ). This is important to understand in light of the proceeding test reaction outcomes (i.e., beliefs about actual test performance). The proceeding section present the results of participants' general testing and math ability perceptions.

Refer to Table 3 for the following section of results. A first measure of evaluative anxiety, in response to the math testing, was assessed in terms of overall feelings of testing anxiety after taking the math test. Older women reported significantly higher test anxiety at the .01 level $(t(113)=-1.15, p<.01$. A second evaluative anxiety measure assessed one's perceptions of social derogation from personal testing performance. In comparison to younger women, older were significantly higher on social derogation anxiety from testing performance women $(t(113)$ $=-2.28, p<.01)$. A third measure examined one's perceived physical tenseness in response to testing. As with the other outcomes, older women $(t(113)=-2.04, p<.001$ reported significantly higher feelings of physical tension as a testing reaction. The final measure of evaluative anxiety assessed one's feelings of cognitive obstruction (i.e., thought disruption) due to testing involvement. Interestingly, there were no significant age level differences on this measure $(t(113)=.48, p>.05)$.

Table 3. Means (M) and standard deviations (SD) of math-related evaluation anxiety and associated scores by age level

\begin{tabular}{lll}
\hline & $\begin{array}{l}\text { Younger } \\
(n=78) \\
M(S D)\end{array}$ & $\begin{array}{l}\text { Older } \\
(n=36) \\
M(S D)\end{array}$ \\
\hline Overall test anxiety & $23.2(2.2)$ & $27.2(1.9)$ \\
\hline Social derogation & $25.6(1.9)$ & $31.5(1.4)$ \\
\hline Evaluation apprehension & $17.9(2.2)$ & $20.8(3.6)$ \\
\hline Physical tenseness & $16.8(1.1)$ & $21.1(3.5)$ \\
\hline Cognitive obstruction & $27.7(1.4)$ & $27.0(1.5)$ \\
\hline Stereotype threat belief & $9.6(1.6)$ & $12.4(1.7)$ \\
\hline Malleability of intelligence belief & $4.8(1.1)$ & $4.1(3.5)$ \\
\hline
\end{tabular}

In addition to evaluation anxiety measures, participants' beliefs in stereotype threat and the malleability of intelligence (i.e., degree of rigidity in intelligence over time) was assessed. There was a significant difference by age level with both stereotype threat belief $(t(113)=-2.26$, $p<.001)$ and for belief in malleability of intelligence $(t(113)=3.14, p<.001)$, with older women in the study reporting significantly higher negative stereotype threat reactions and significantly lower positive belief in later-life learning ability. Belief in the malleability of intelligence (i.e., higher score indicated belief in increasing rigidity in intelligence) was significantly related to math-related social derogation $(r=.44, p<.001)$, physical tenseness ( $r$ $=.29, p<.01)$, overall math test anxiety $(r=.37, p<.001)$, and actual math test performance $(r$ $=-.29, p<.01)$. The proceeding section present the results of participants' math-related attitudinal and performance outcomes by instructional condition. 
8.2 Hypothesis \#2: Instructional Condition Comparisons in Math-related Outcomes

The second study hypothesis examined whether there were significant differences in reported math attitudes (e.g., stereotype threat reaction) and/or test performance among participants between the four instructional conditions. Refer to Table 4 for this section of results. Both traditional and non-traditional women learners were randomly assigned to one of the four conditions. Examining women learners' self-reported feelings of general evaluation apprehension, there were significant differences between women learners in the four instructional conditions $(F(3,110)=134.738, p<.001)$. Post hoc (Tukey) analyses indicated that women learners in the "math as language/competency enhancing" condition reported significantly lower feelings of general evaluation apprehension.

Table 4. Means (M) and standard deviations (SD of math-related outcomes by the four instructional conditions

\begin{tabular}{lllll} 
& $\begin{array}{c}\text { "Language/ } \\
\text { Enhancing” } \\
(n=28) \\
M(S D)\end{array}$ & $\begin{array}{c}\text { "Language/ } \\
\text { Destroying” } \\
(n=29)\end{array}$ & $\begin{array}{c}\text { "Numbers/ } \\
\text { Enhancing” } \\
(n=29)\end{array}$ & $\begin{array}{l}\text { "Numbers/ } \\
\text { Destroying” } \\
(n=28)\end{array}$ \\
Outcome & $26.3(2.5)$ & $22.3(1.8)$ & $19.2(2.1)$ & $16.1(1.4)$ \\
\hline Math test score & $13.4(1.3)$ & $16.2(1.1)$ & $24.1(1.2)$ & $25.1(1.0)$ \\
\hline Math self-efficacy score & $14.2(0.9)$ & $18.3(1.2)$ & $23.7(1.1)$ & $24.3(0.8)$ \\
\hline Math anxiety score & $6.6(0.2)$ & $6.1(0.7)$ & $8.2(0.3)$ & $8.1(0.4)$ \\
\hline Math study time (estimated) & $5.9(0.4)$ & $4.7(0.8)$ & $9.8(0.2)$ & $9.9(0.3)$ \\
\hline Math study time (actual) & & & &
\end{tabular}

As explained in the previous section, higher scores on the math self-efficacy measure indicated lower levels of math-related self-efficacy and associated negative reactions. There were significant differences in scores between the four instructional conditions on math-related self-efficacy (higher scores) at the .001 level $(F(3,110)=710.330, p<.001)$ and math anxiety at the .001 level $(F(3,110)=626.977, p<.001)$. Post hoc (Tukey) analyses indicated that women learners in both of the "math as numbers" conditions reported significantly lower feelings of math self efficacy and significantly higher math anxiety $(p<.001)$.

Interestingly, both older and younger women's estimated and actual study time (minutes) was significantly higher among learners in both "math as numbers" conditions in comparison to the "math as language" conditions $(F(3,110)=163.652, p<.001)$. Finally, and most significant of all, was that there was a significant differences in actual test performance by instructional condition $(F(3,110)=871.786, p<.001)$. Post hoc (Tukey) analyses suggested that both younger and older women learners performing significantly better on the math test under the "math as language/competency enhancing" study and testing condition than learners assigned to the other three learning conditions.

\subsection{Hypothesis \#3: Qualitative Examination of Past Math-related Role Models’ Impact}

The last study hypothesis examined whether there was a meaningful and long-term impact of past math-related role model on women's self-reported feelings of math self efficacy. In the 
post-testing phase of the study, a majority of both younger and older women interviewed (83\%) reported having at least one math-related role model during their impressionable elementary/ middle school education years in the form of teachers, coaches, and parents. Of these different types of role models, participants predominantly reported more negative stereotypes from early teachers about girls' ability to perform well in math tasks. Parents, especially mothers, tended to communicate many more messages of neutral or positive messages of math abilities to daughters. There was no apparent cohort difference between the two age groups regarding the prevalence of stereotyping. This balance of positive and negative "messages" about personal math ability was reported as having a persistent impact on women's later math self-concept into early and later life.

\section{Discussion}

As the mean age of the U.S. population rises, it can be expected that there will be a growing number of older "non-traditional" college learners on college campuses in the coming decades (Silverstein, Choi, \& Bulot, 2001) and understanding their preferences and needs will become an increasing important focus for instructors (Strage, 2008). From a life-long learning perspective, educators and practitioners related to the field of aging need to re-examine the perceived issues of accessibility, motivational factors, and quality of learning opportunities for non-traditional, older learners (e.g., Kaufman, Agars, \& Lopez-Wagner, 2008; Lyons, 2006; Principi \& Lamura, 2009). Peterson (1983) suggested more than thirty years ago that educators need to focus on designing learning environments which effectively reduce a "sense of fear of failure" and "the chance of being made to look foolish" (p. 87) for older learners. As educators, it is vital to identify impediments to learning so appropriate, supporting instructional interventions may be implemented in the classroom.

Perceived barriers to learning and the perceived ability to learn new concepts can significantly impact older adults' academic performance, their willingness to engage in life-long learning, and their general quality of life and coping ability (e.g., Bertera, Bertera, Morgan, Wuertz, \& Attey, 2007). “Messages” from significant role models in a woman's life (e.g., teachers, parents) can have an important impact on how she conceptualizes personal strengths and limitations in performance (e.g., parents of girls and math skill perceptions; Yee \& Eccles, 1988). More than fifteen years ago, Sogruno (1998) raised the issue of better understanding factors underlying older learners' evaluative anxieties, and its impact on their motivation level and performance in educational settings. Access and participation in education across the life span is related to quality of life and is the key for advancement in society and one's career for most people, being inextricably linked to financial security, access to resources, and aspects of mental health (Principi \& Lamura, 2009; Waller, 2006). The following will explain how adult learners' perceptions of the instructional and/or assessment environment can have a significant impact on the quality of their education experiences.

Overall study results do support the idea of an aging- and/or cohort-related “decrement" stereotype threat belief about performance capabilities in these types of evaluative tasks (e.g., Hertzog, 2008). The non-traditional” women participants' tended to exhibit less efficacious 
beliefs about performance capability, in general about testing and specific Math ability, and associated behavioral outcomes (i.e., significantly higher study time spent). This negative evaluation of performance concerns amongst the "non-traditional" learners indicates a stereotype threat reaction. This supposition is further substantiated by the results that these older students in the present study were also likely to score significantly higher (more negative) in stereotype threat belief and aging perceptions scores. This finding of preliminary support for the existence of a "decrement" stereotype threat phenomenon is especially interesting when there were no significant differences in actual math test performance, which by extension may be reflected in other performance domains with older adults (e.g., balancing a checkbook). This apparent lack of correspondence between emotional reactions and cognitive processes during task performance may belie a less effective "meta-cognitive" self-awareness among older learners (e.g., Justice \& Dornan, 2001). Follow up older learner research should examine this preliminary finding within the context of math-related instruction.

The positive impact of the "math as language/competency enhancing” instructional condition in preliminary results appeared to benefit both younger and older women learners in both personal attitudes toward math ability, general learning capability, and testing performance behaviors. One might speculate that both younger and older women have the "positive" social stereotype of being higher in verbal intelligence (e.g., "stereotype lift"; Johnson, Barnard-Brak, Saxon, \& Johnson, 2012), and this "self-schema" may have generalized and overridden the comparatively negative math self-schema, again stereotyped, that women may have internalized over time. It is important to understand how spatial ability and other individual difference factors relate to this "lift" schema process elicited during math learning (Maloney, Waechter, Risko, \& Fugelsang, 2012). A better understanding the "roots" of these lift schemas in response to math-related role models (e.g., parents and/or early teachers in the educational process) (e.g., Gunderson, Ramirez, Levine, \& Beilock, 2012) warrants further future investigation with a growing aging population of learners.

\section{Limitations of the Study and Future Research Suggestions}

The present research would have benefitted from having a larger sample of non-traditional women learners and a non-college sample. Future research should extend the preliminary findings from the present research to studying both men and women across multiple age (cohort) groups. More instructional techniques and individual-difference factors (e.g., the role of culture on gender role expectations) should also be explored in future research.

\section{Contributions of the Present Research to Field Knowledge}

These current study findings are important to examine and apply in educational designs for life-long learners. As educators, it is an ethical imperative to focus on the "internal" barriers to life-long learning opportunities (Hollis-Sawyer \& Sawyer, 2008; Sawyer \& Hollis-Sawyer, 2005; Willis, 1985). With these same efforts toward positive educational design, early socialization and associated life-long adaptation issues for aging non-traditional learners need 
further investigation to identify effective "positive" messages in education settings (e.g., Peterson, 1983). This knowledge can then be effectively generalized to societal educational efforts through life-span community-based and/or workplace training programs.

\section{References}

Aronson, J., Quinn, D. M., \& Spencer, S. J. (1998). Stereotype threat and the academic underperformance of minorities and women. In Swim, J. K. \& Stangor, C. (Eds), Prejudice: The target's perspective (pp. 83-103). San Diego, CA: Academic Press, Inc.

Bandalos, D. L., Yates, K., \& Thorndike-Christ, T. (1995). Effects of statistics self-concept, perceived self-efficacy, and attributions for failure and success on test anxiety. Journal of Educational Psychology, 87(4), 611-623. http://dx.doi.org/10.1037/0022-0663.87.4.611

Beilock, S. L., Jellison, W. A., Rydell, R. J., McConnell, A. R., \& Carr, T. H. (2006). On the causal mechanisms of stereotype threat: Can skills that don't rely heavily on working memory still be threatened? Personality and Social Psychology Bulletin, 32(8), 1059-1071. http://dx.doi.org/10.1177/0146167206288489

Bertera, E. M., Bertera, R. L., Morgan, R., Wuertz, E., \& Attey, A. M. O. (2007). Training older adults to access health information. Educational Gerontology, 33(6), 483-500. http://dx.doi.org/10.1080/03601270701328250

Betz, N. E. (1978). Prevalence, distribution, and correlates of statistics anxiety in college students. Journal of Counseling Psychology, 25(5), 441-448.

Bleeker, M. M., \& Jacobs, J. E. (2004). Achievement in statistics and science: Do mothers' beliefs matter 12 years later? Journal of Educational Psychology, 96(1), 97-109. http://dx.doi.org/10.1037/0022-0663.96.1.97

Brodish, A. B., \& Devine, P. G. (2009). The role of performance-avoidance goals and worry in mediating the relationship between stereotype threat and performance. Journal of $\begin{array}{llll}\text { Experimental Social } & \text { Psychology, } & \text { 45(1), }\end{array}$ http://dx.doi.org/10.1016/j.jesp.2008.08.005

Cook, R. P. (1998). An exploration of the relationship between mathematics anxiety level and perceptual learning style of adult learners in a community college setting. Unpublished dissertation manuscript.

Cross, W., \& Florio, C. (1978). You are never too old to learn (pp. 9-11). New York: McGraw-Hill.

Drummond, R. J., \& Gilkison, B. (1989). Predictors of academic self-concept of older adults. Psychological Reports, 65(3, Pt 1), 771-774. http://dx.doi.org/10.2466/pr0.1989.65.3.771

Dweck, C. S., Chiu, C., \& Hong, Y. (1995). Implicit theories: Elaboration and extension of the model. Psychological Inquiry, 6, 322-333. http://dx.doi.org/10.1207/s15327965pli-0604_12 
Eccles, J. S., \& Jacobs, J. E. (1986). Social forces shape math attitudes and performance. Signs: Journal of Women in Culture and Society, 11, 367-380. http://www.jstor.org/stable/3174058

Friedman, I. A., \& Bendas-Jacob, O. (1997). Measuring perceived test anxiety in adolescents: A self report scale. Educational \& Psychological Measurement, 57(6), 1035-1046. http://dx.doi.org/10.1177/0013164497057006012

Galbraith, M. W., \& James, W. B. (1984). Assessment of dominant perceptual learning styles of older adults. Educational Gerontology, 10(6), 449-457. http://dx.doi.org/10.1080/0380127840100603

Galdi, S., Cadinu, M., \& Tomasetto, C. (2014). The roots of stereotype threat: When automatic associations disrupt girls' math performance. Child Development, 85, 250-263. http://dx.doi.org/10.1111/cdev.12128

Griggs, M. S., Rimm-Kaufman, S. E., Merritt, E. G., \& Patton, C. L. (2013). The responsive classroom approach and fifth grade students' math and science anxiety and self-efficacy. School Psychology Quarterly, 28, 360-373. http://dx.doi.org/10.1037/spq0000026

Grimm, L. R., Markman, A. B., Maddox, W. T., \& Baldwin, G. C. (2009). Stereotype threat reinterpreted as a regulatory mismatch. Journal of Personality and Social Psychology, 96(2), 288-304. http://dx.doi.org/10.1037/a0013463

Gunderson, E. A, Ramirez, G., Levine, S. C., \& Beilock, S. L. (2012). The role of parents and teachers in the development of gender-related math attitudes. Sex Roles, 66, 153-166. http://dx.doi.org/10.1007/s11199-011-9996-2

Haack, D. G. (1979). Teaching statistical literacy. Teaching Statistics, 1(3), 74-76.

Hart, S. A., Petrill, S. A., Thompson, L. A., \& Plomin, R. (2009). The ABCs of math: A genetic analysis of mathematics and its links with reading ability and general cognitive ability. Journal of Educational Psychology, 101(2), 388-402. http://dx.doi.org/10.1037/a0015115

Hartman, M., \& Hartman, H. (2008). How undergraduate engineering students perceive women's (and men's) problems in science, math and engineering. Sex Roles, 58(3-4), 251-265. http://dx.doi.org/10.1007/s11199-007-9327-9

Hertzog, C. (2008). Theoretical approaches to the study of cognitive aging: An individual differences perspective. In Hofer, S. M. \& Alwin, D. F. (Eds), Handbook of cognitive aging: Interdisciplinary perspectives (pp. 34-49). Thousand Oaks, CA: Sage.

Hollis-Sawyer, L. A., \& Sawyer, T. P. (2008). Potential stereotype threat and face validity effects on cognitive-based test performance in the classroom. Educational Psychology, 28(3), 291-304. http://dx.doi.org/10.1080/01443410701532313

Holtzclaw, L. R. (1985). The importance of self-concept for the older adult. Journal of Religion \& Aging, 1(3), 23-29. http://dx.doi.org/10.1300/J491v01n03_02 
Hopko, D. R., Ashcraft, M. H., Gute, J., Ruggiero, K. J., \& Lewis, C. (1998). Mathematics anxiety and working memory: Support for the existence of a deficient inhibition mechanism. Journal of Anxiety Disorders, 12(4), 343-355. http://dx.doi.org/10.1016/S0887-6185(98)00019-X

Howard, D. V., \& Wiggs, C. L. (1993). Aging and learning: Insights from implicit and explicit tests. In Cerella, J., \& Rybash, J. M. (Eds.), Adult information processing: Limits on loss (pp. 511-527). San Diego, CA: Academic Press.

Hunsley, J., \& Flessati, S. L. (1988). Sex and mathematics anxiety: The role of math-related experiences and opinions. Anxiety Research, 1(3), 215-224. http://dx.doi.org/10.1080/0891777- 8808248720

Johnson, H. J., Barnard-Brak, L., Saxon, T. F., \& Johnson, M. K. (2012). An experimental study of the effects of stereotype threat and stereotype lift on men and women's performance in mathematics. Journal of Experimental Education, 80, 137-149. http://dx.doi.org/10.1080/ 00220973.2011.567312

Justice, E. M., \& Dornan, T. M. (2001). Metacognitive differences between traditional-age and nontraditional-age college students. Adult Education Quarterly, 51(3), 236-249. http://dx.doi.org/10.1177/07417130122087269

Kaufman, J. C., Agars, M. D., \& Lopez-Wagner, M. C. (2008). The role of personality and motivation in predicting early college academic success in non-traditional students at a Hispanic-serving institution. Learning and Individual Differences, 18(4), 492-496. http://dx.doi.org/10.1016/j.lindif.2007.11.004

Kostka, M. P., \& Wilson, C. K. (1986). Reducing mathematics anxiety in nontraditional-age female students. Journal of College Student Personnel, 27(6), 530-534.

Kuznar, E., Falciglia, G. A., Wood, L., \& Frankel, J. (1991). Learning style preferences: A comparison of younger and older adult females. Journal of Nutrition for the Elderly, 10(3), 21-33. http://dx.doi.org/10.1300/J052v10n03_02

Kyttala, M., \& Bjorn, P. M. (2014). The role of literacy skills in adolescents' mathematics word problem performance: Controlling for visuo-spatial ability and mathematics anxiety. Learning and Individual Differences, 29, 59-66. http://dx.doi.org/10.1016/ j.lindif.2013.10.010

Lemieux, A. (1997). Essential learning contents in the curriculum for a certificate degree in personalized education for older adults. Educational Gerontology, 23(2), 143-150. http://dx.doi.org/10.1080/0360127970230205

Llabre, M. M., \& Suarez, E. (1985). Predicting math anxiety and course performance in college women and men. Journal of Counseling Psychology, 32(2), 283-287. http://dx.doi.org/10.1037/0022-0167.32.2.283

Luckie, J. C. (1999). Case studies on success variables in older adult learner programs. Educational Gerontology, 25(3), 253-268. http://dx.doi.org/10.1080/036012799267864 
Lynch, A. Q., \& Sellers, P. A. (1996). Preferences for different educational environments and psychological type: A comparison of adult learners and traditional age college students. Journal of Psychological Type, 39, 18-29.

Lyons, J. (2006). An exploration into factors that impact upon the learning of students from nontraditional backgrounds. Accounting Education, 15(3), 325-334.

Major, B., Spencer, S. J., Schmader, T., Wolfe, C., \& Crocker, J. (1998). Coping with negative stereotypes about intellectual performance: The role of psychological disengagement. Personality and Social Psychology Bulletin, 24, 34-50. http://dx.doi.org/10.1177/0146167298241003

Maloney, E. A, Waechter, S., Risko, E. F., \& Fugelsang, J. A. (2012). Reducing the sex difference in math anxiety: The role of spatial processing ability. Learning and Individual Differences, 22, 380-384. http://dx.doi.org/10.1016/j.lindif.2012.01.001

O'Brien, L. T., \& Crandall, C. S. (2003). Stereotype threat and arousal: Effects on women's statistics performance. Personality and Social Psychology Bulletin, 29(6), 782-789. http://dx.doi.org/10.1177/0146167203029006010

O'Connor, D. M. (1987). Elders and higher education: Instrumental or expressive goals? Educational Gerontology, 13(6), 511-519. http://dx.doi.org/10.1080/0360127870130607

Peterson, D. A. (1983). Facilitating education for older learners. San Francisco, CA: Jossey-Bass.

Principi, A., \& Lamura, G. (2009). Education for older people in Italy. Educational Gerontology, 35(3), 246-259. http://dx.doi.org/10.1080/03601270802611349

Sawyer, T. P., Jr., \& Hollis-Sawyer, L. A. (2005). A path-analytic assessment of different stress coping models in predicting stereotype threat perceptions, test anxiety reactions, and cognitive test performance. International Journal of Testing, 5(3), 225-246. http://dx.doi.org/10.1207/s15327574ijt0503_3

Schweinle, A., \& Mims, G. A. (2010). Mathematics self-efficacy: Stereotype threat versus resilience. Social Psychology of Education, 12(4), 501-514.

Shaughnessy, M. F., \& Reif, L. (1987). An investigation of differential encoding and retrieval by older adult college students. Psychological Reports, 61(3), 735-740. http://dx.doi.org/10.2466/pr0.1987.61.3.735

Silverstein, N. M., Choi, L. H., \& Bulot, J. J. (2001). Older learners on campus. Gerontology \& Geriatrics Education, 22(1), 13-30. http://dx.doi.org/10.1300/J021v22n01_02

Sogruno, O. A. (1998). Impact of evaluative anxiety on adult learning. Journal of Research \& Development in Education, 31(2), 109-120.

Spencer, S. J., Steele, C. M., \& Quinn, D. M. (1999). Stereotype threat and women's math performance. Journal of Experimental Social Psychology, 35(1), 4-28. http://dx.doi.org/10.1006/jesp.1998.1373 
Steele, C. M. (1997). A threat in the air: How stereotypes shape intellectual identity and performance. American $\quad$ Psychologist, 52(6), 613-629. http://dx.doi.org/10.1037/0003-066X.52.6.613

Steele, C. M., \& Aronson, J. (1995). Stereotype threat and the intellectual test performance of African Americans. Journal of Personality \& Social Psychology, 69(5), 797-811. http://dx.doi.org/10.1037/0022-3514.69.5.797

Steele, C. S., \& Ambady, N. A. (2006). "Statistics is hard!" The effect of gender priming on women's attitudes. Journal of Experimental Social Psychology, 42, 428-436. http://dx.doi.org/10.1016/j.jesp.2005.06.003

Strage, A. (2008). Traditional and non-traditional college students' descriptions of the "ideal" professor and the "ideal" course and perceived strengths and limitations. College Student Journal, 42(1), 225-231.

U.S. Education Department, National Center for Education Statistics (2008). Projections of education statistics to 2016 (NCES: 2008-060). Washington, DC: National Center for Educational Statistics.

Waller, B. (2006). Math interest and choice intentions of non-traditional African-American college students. Journal of Vocational Behavior, 68(3), 538-547. http://dx.doi.org/10.1016/ j.jvb.2005.12.002

Willis, S. L. (1985). Towards an educational psychology of the older adult learner: Intellectual and cognitive bases. In Birren, J. E., \& Schaie, K. W. (Eds.), Handbook of the psychology of aging (2nd ed.) (pp. 818-847). New York, NY: Van Nostrand Reinhold Co, Inc.

Yee, D. K., \& Eccles, J. S. (1988). Parent perceptions and attributions for children's math achievement. Sex Roles, 19, 317-333. http://dx.doi.org/10.1007/BF00289840

\section{Copyright Disclaimer}

Copyright reserved by the author(s).

This article is an open-access article distributed under the terms and conditions of the Creative Commons Attribution license (http://creativecommons.org/licenses/by/3.0/). 